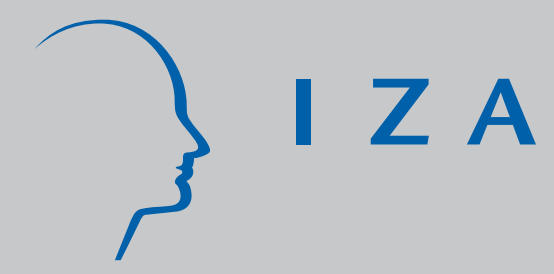

IZA DP No. 855

Career Concerns in a Simple Experimental Labour Market

Bernd Irlenbusch

Dirk Sliwka

August 2003 


\title{
Career Concerns in a Simple Experimental Labour Market
}

\author{
Bernd Irlenbusch \\ University of Erfurt \\ Dirk Sliwka \\ University of Bonn and IZA Bonn
}

Discussion Paper No. 855
August 2003

IZA

P.O. Box 7240

D-53072 Bonn

Germany

Tel.: +49-228-3894-0

Fax: +49-228-3894-210

Email: iza@iza.org

This Discussion Paper is issued within the framework of IZA's research area Mobility and Flexibility of Labor. Any opinions expressed here are those of the author(s) and not those of the institute. Research disseminated by IZA may include views on policy, but the institute itself takes no institutional policy positions.

The Institute for the Study of Labor (IZA) in Bonn is a local and virtual international research center and a place of communication between science, politics and business. IZA is an independent, nonprofit limited liability company (Gesellschaft mit beschränkter Haftung) supported by Deutsche Post World Net. The center is associated with the University of Bonn and offers a stimulating research environment through its research networks, research support, and visitors and doctoral programs. IZA engages in (i) original and internationally competitive research in all fields of labor economics, (ii) development of policy concepts, and (iii) dissemination of research results and concepts to the interested public. The current research program deals with (1) mobility and flexibility of labor, (2) internationalization of labor markets, (3) welfare state and labor market, (4) labor markets in transition countries, (5) the future of labor, (6) evaluation of labor market policies and projects and (7) general labor economics.

IZA Discussion Papers often represent preliminary work and are circulated to encourage discussion. Citation of such a paper should account for its provisional character. A revised version may be available on the IZA website (www.iza.org) or directly from the author. 
IZA Discussion Paper No. 855

August 2003

\section{ABSTRACT}

\section{Career Concerns in a Simple Experimental Labour Market ${ }^{*}$}

We experimentally investigate a simple version of Holmström's career concerns model in which firms compete for agents in two consecutive periods. Profits of firms are determined by agents' unknown ability and the effort they choose. Before making second-period wage offers firms are informed about first-period profits. In a different treatment firms additionally learn the abilities of agents. Theory suggests high first-period equilibrium effort in the hidden ability treatment but no effort elsewhere. However, we find that effort is significantly higher in the revealed ability treatment and therefore conclude that transparency does not weaken, but strengthen career concerns incentives.

JEL Classification: C72, C91, J33

Keywords: incentives, labour market, reputation, reciprocity, career concerns

Corresponding author:

Dirk Sliwka

Betriebswirtschaftliche Abteilung II

University of Bonn

Adenauerallee 24-42

53113 Bonn

Germany

Tel.: +49228739214

Fax: +49228 739210

Email: dirk.sliwka@uni-bonn.de

* The authors are thankful for the suggestions made by two anonymous referees. Jörg Breitung and Simon Gächter provided valuable comments. All errors are our own. Financial support by the Deutsche Forschungsgemeinschaft through grant KR2077/2-1 and the European Union through the EU-TMR Research Network ENDEAR (FMRX-CT98-0238) is gratefully acknowledged. 


\section{Introduction}

Since Holmström's (1982) article, building on the work by Fama (1980), the understanding has become well established that career concerns are an important incentive device. ${ }^{1}$ Holmström's idea is basically the following: the performance of a manager depends on two factors, his ability and his effort at each point in time. After each period in the working life of a manager the actual and potential other employers receive a signal on the manager's performance. However, they cannot distinguish directly whether good performance was due high ability or high effort. Potential employers can make wage offers to a manager, which will be contingent on their beliefs about his ability and effort choice. Their beliefs depend on their observations of past performance. Given an equilibrium effort level, the labour market's beliefs about the manager's ability will be higher, the higher the manager's past output. As a consequence, by exerting effort in the actual period the manager can raise the market's beliefs on his ability and, hence, the wages he receives in the future - therefore this type of models is sometimes described as "signal jamming" models.

One important implication of this theory is that managers will exert higher effort in the beginning of their career than in the end. In the beginning, there are not so many signals of past performance available to judge the ability of a manager. Hence, initial performance has a high impact on the labour market's assessment of the manager's ability and therefore the manager's marginal return on effort is high. In the end of his career, there has been a large number of signals on a manager's ability. Then, current performance has only a small effect on the market's assessments. In addition, the number of remaining periods is small in which the manager would receive wages raised by current higher performance.

This mechanism seems to be highly plausible and might well explain certain aspects of career concerns as an incentive device. However, it builds on the important assumption that the market cannot distinguish between a manager's ability and his effort choice. If such a distinction is feasible the manager is not able to "fool" the labour market into believing that he is of high ability when he is not. A backward induction argument then leads to the conclusion that a rational agent with self-regarding preferences will never exert any positive effort. Hence, if the labour market is able to differentiate between ability and effort the mechanism should break down entirely.

1 Other articles building on this idea are for instance Gibbons and Murphy (1992) or Anderson (2002) who analyse the interaction of career concerns with piece rates. Auriol, Friebel, Pechlivanos (2002) consider the interaction of career concerns and explicit incentives in teams. Dewatripont, Jewitt and Tirole (1999a) and 
Recent literature in experimental economics (e.g. Fehr, Kirchsteiger and Riedl 1993; Berg, Dickhaut, and McCabe 1995, Fehr, Gächter and Kirchsteiger 1997, Charness 1998, Abbink, Irlenbusch, and Renner 2000, Dufwenberg and Gneezy 2000, Dufwenberg and Kirchsteiger 2000, Fehr and Schmidt 2000, Clark and Sefton 2001, Van der Heijden, Nelissen, Potters, and Verbon 2001, Irlenbusch and Sliwka 2003) has pointed out that the assumption that economic agents are guided by narrow self-interest and maximisation of monetary payoffs has to be rejected in many cases. Fairness and reciprocity play an important role in explaining human behaviour. Since a principal may have a preference for hiring an agent who is willing to reciprocate generous wages with non-zero effort even in the end of the game, we should expect that it is attractive for agents to reciprocate wage offers right from the beginning. Hence, it is likely that agents exert strictly positive effort levels even when ability and effort can be distinguished.

In order to analyse the functioning of the career concerns mechanism empirically, we designed an experimental setting which to our knowledge is the first attempt to implement a career concerns model in a laboratory experiment. The experimental approach has the advantage that it provides data of real behaviour in situations which differ only in the strategic variation which we are interested in. We examine two different settings. In a first setting we implement a simple version of Holmström's model, making the key assumption that a manager's ability and effort cannot be observed separately. We contrast this with a second setting where effort and ability are revealed, in order to examine the consequences of omitting the essential "indistinguishability" assumption. Note that the second setting still allows for building a reputation for reciprocating positive wage offers.

In our experiment four firms can bid for the service of three managers in each of two consecutive periods. The managers' abilities are initially randomly drawn, but fixed for both periods. A manager can accept only one offer in each period. After having accepted an offer he can choose an effort level. The firm, whose bid he has accepted, receives simply the sum of his ability and his effort. In the first setting only this sum is conveyed, in the second the manager's ability is revealed in addition to all potential employers. Theory predicts high effort in the first period of the setting with hidden abilities and no effort at all in all other cases.

We basically find two interesting observations. First, in both settings effort levels are positive and they are higher in the first than in the second period, i.e. even if the ability is revealed.

(1999b) extend Holmström's framework for instance to encompass multiple tasks or more general distribution functions. See also Gibbons and Waldman (1999) for an overview. 
Hence, it is not only the strategic "signal jamming" motive - that is to make the labour market think that oneself is of high ability - that induces high efforts. Second and most surprisingly, it turns out that the effect is much stronger when abilities are revealed. First period efforts are significantly higher in that case. Hence, the experimental results turn the theoretical view upside down: we observe even higher efforts in the treatment where according to standard theory the absence of uncertainty prevents effort!

The paper proceeds as follows. In section 2 we present a simple version of a Holmström-type career concerns model and give equilibrium solutions in section 3 for both the hidden ability and the revealed ability setting. In section 4 the experimental design is described. After this we report the experimental results in section 5. Finally, possible interpretations are discussed in section 6.

\section{A Simple Career Concerns Model}

In this section we provide a simple version of a Holmström (1982)-type career concerns model. Whereas Holmström considers several periods we consider only two. ${ }^{2}$ Instead of normally distributed abilities we assume a uniform distribution and omit additional noise terms. This gives us a clear-cut setup containing the basic ingredients of a career concerns model without imposing too much complexity that may not be understood by experimental participants. In addition, normally distributed random variables cannot be implemented experimentally without skipping the tails as they always encompass the possibility of infinite losses or gains. Furthermore the inclusion of additional noise terms would make Bayesian updating of beliefs about an agent's ability much more complex.

In our model a manager works for two consecutive periods $t=1,2$ and produces a certain output in each period. This output is determined by the manager's ability $a$ and the effort he exerts in period $t$ denoted by $e_{t}$. The output accrues to the manager's employer in the respective period. The manager's ability is constant over both periods. In the beginning this ability is unknown to all players, i.e. even the managers themselves do not observe their own ability. It is known, however, that the ability is uniformly distributed on the set $[0, A]$. For simplicity we assume that the output $y_{t}$ in period $t$ is given by the sum of the manager's ability and the effort he exerted in this period:

\footnotetext{
${ }^{2}$ This is for instance also done in Dewatripont, Jewitt and Tirole (1999a) and (1999b), Anderson (2002) or Auriol, Friebel, Pechlivanos (2002)
} 


$$
y_{t}=e_{t}+a
$$

There are at least two firms present in the market, which as potential employers compete for the managers' services in each period. In the beginning of each period all firms simultaneously make a fixed wage offer to the manager. A manager can accept one of those offers.

We consider two different settings, which will be implemented in the experiment. They differ with regard to the amount of information the potential employers receive about the manager's past performance. In both settings all potential employers observe the output produced by the manager in the first period before they make their second period wage offers. First, we analyse a standard Holmström type model, which we call the hidden ability setting. In this setting although observing the manager's output, the potential employers do not learn to which parts it consists of the manager's ability and effort. Then we look at a second setting, which we call the revealed ability setting, where the employers learn in addition to the output its exact composition. Hence, before they make their second period wage offers they know precisely a manager's ability. Note that, as the manager himself learns the first period output and knows his own effort choice, he perfectly knows his ability after period 1 in both treatments.

After the manager has chosen one of the offers in period $t$, he receives the offered wage $w_{t}$, that is paid by the firm which has made this offer. After this, he can choose an effort level $e_{t}$, which will lead to private costs $c\left(e_{t}\right)$ for the manager, where $c(0)=0, c^{\prime}\left(e_{t}\right)>0$ and $c^{\prime \prime}\left(e_{t}\right)>0$. The timeline of events in both settings is as follows:

\begin{tabular}{|c|c|c|c|c|c|}
\hline \multicolumn{3}{|c|}{ Period 1} & \multicolumn{3}{|c|}{ Period 2} \\
\hline+ & + & t & + & + & † \\
\hline $\begin{array}{l}\text { Wage offers } \\
\text { made by firms; }\end{array}$ & $\begin{array}{c}\text { Manager chooses } \\
\text { effort level } e_{1}\end{array}$ & $\begin{array}{l}\text { Output } y_{1} \\
\text { realised }\end{array}$ & $\begin{array}{l}\text { Wage offers } \\
\text { made by firms; }\end{array}$ & $\begin{array}{c}\text { Manager chooses } \\
\text { effort level } e_{2}\end{array}$ & $\begin{array}{l}\text { Output } y_{2} \\
\text { realised }\end{array}$ \\
\hline $\begin{array}{c}\text { Manager selects } \\
\text { one offer }\end{array}$ & & $\begin{array}{c}R A \text {-setting: } \\
\text { ability revealed }\end{array}$ & $\begin{array}{c}\text { Manager selects } \\
\text { one offer }\end{array}$ & & \\
\hline
\end{tabular}

As described above, the only difference between both settings is that in the revealed ability setting in addition to his output all firms perfectly learn the manager's ability.

The profit of a firm when hiring the manager in period $t$ is the difference between his output $y_{t}$ and wage $w_{t}$. The utility of the manager in period $t$ is the difference between the received wage $w_{t}$ and the costs of his effort. For simplicity there is no discounting. 


\section{Equilibrium Behaviour}

We solve for the perfect Bayesian equilibrium of the game described above for both settings. We assume that all players have purely self-regarding preferences and are risk neutral. Risk aversion does not greatly alter the results. We will briefly discuss this at the end of this section.

\subsection{The Hidden Ability Setting}

Clearly, a rational manager with purely self-regarding preferences will never exert any effort in period 2 as this just causes costs without any return. Hence, the value of a manager for potential employers is only determined by his ability. In this setting the potential employers do not learn the agent's ability directly after period 1. However, in a pure strategy equilibrium, they can infer the ability from the first period result. With an equilibrium effort of $e_{1}{ }^{*}$ a potential employer can easily compute the actual ability $a$ of an employee. It is simply the difference between $y_{1}$ and $e_{1}^{*}$ :

$$
a=y_{1}-e_{1}^{*}
$$

Thus, all market participants precisely know the ability of a manager after period 1 and they have a common valuation of his services. The bidding process at the beginning of period 2 results in Bertrand competition. In equilibrium the second period wage must correspond to the ability of the manager, so that $w_{2}=y_{1}-e_{1}^{*}$.

This wage setting behaviour is anticipated by the manager in period 1. The market's beliefs on his ability are influenced by his effort choice. By exerting more effort in the first period he can raise the market's expectations and, consequently, second period wages as he can raise $y_{1}$ and therefore $w_{2}$. Recall that $e_{1}{ }^{*}$ describes the firms' beliefs on his equilibrium effort. In equilibrium those beliefs must be accurate. It remains to analyse which values for $e_{1}$ can indeed be equilibrium values.

Note that, when the manager chooses a value of $e_{1}$ different from $e_{1}{ }^{*}$, the revenue observed by the market may well attain values which can never occur on the equilibrium path. It seems to be reasonable to assume that firms' conditional expectations about the manager's ability are monotonically increasing in $y_{1}$ not only on but also off the equilibrium path: When (rationally) believing that the manager's ability is 0 when observing revenue $e_{1}{ }^{*}$ why should firms believe that he has a higher ability after lower realizations of the revenue? If we impose 
this "refinement" ${ }^{\prime}$ we must have that the conditional expectation on $a$ is zero for all observations $y_{1}$ smaller than $e_{1}{ }^{*}$ (as in equilibrium $a$ is believed to be equal to zero if $y_{1}=e_{1}{ }^{*}$ ) and conversely, $a$ is believed to be equal to $A$ for all $y_{1}$ larger than $A+e_{1}{ }^{*}$. Hence,

$$
w_{2}\left(y_{1}\right)= \begin{cases}0 & \text { if } y_{1}<e_{1}^{*} \\ y_{1}-e_{1}^{*} & \text { if } e_{1}^{*} \leq y_{1} \leq e_{1}^{*}+A \\ A & \text { if } y_{1}>e_{1}^{*}+A\end{cases}
$$

In period 1 the agent maximizes

$$
\left.\max _{e_{1}} E\left[w_{2}\left(y_{1}\right)\right) e_{1}\right]-c\left(e_{1}\right)
$$

Increasing the effort by one unit will increase $y_{1}$ also by one unit and - in equilibrium - the agent's future wage by the same amount. Hence, we get the direct conjecture that $c^{\prime}\left(e_{1}{ }^{*}\right)=1$. In the appendix we show that this equation indeed defines the unique pure strategy equilibrium. The existence of this equilibrium is assured if there is sufficiently high uncertainty about the agent's ability, i.e. for sufficiently large values of $A$.

Note, that the first period equilibrium effort actually corresponds to the first-best-effort, as the marginal product of effort for the manager exactly corresponds to the marginal product of effort for the firm. Thus, in the simple model considered here career concerns lead to efficient effort levels in the first period although wages are fixed. This is due to the fact that here output only depends on effort and ability of the manager. In Holmström's (1982) model and for instance in the papers by Dewatripont, Jewitt and Tirole (1999) there is additional noise. Thus, the current output has a weaker impact on the market's assessments and the manager therefore exerts less effort.

It remains to compute the first period equilibrium wage. Again there is Bertrand competition among the potential employers. The wage will correspond to the expected output in period 1 which is simply the sum of the expected ability of the manager $E[a]$ and the equilibrium effort level $e_{1}^{*}$ :

$$
w_{1}=E[a]+e_{1}^{*}
$$

These results can be summarised as follows:

\footnotetext{
${ }^{3}$ In signalling games similar refinements have been applied recently by e.g. Fehr, Klein and Schmidt (2002) or Bénabou and Tirole (2002).
} 


\section{Theoretical Result 1: (Hidden Ability Setting)}

If $A$ is sufficiently large, there is a perfect Bayesian equilibrium in pure strategies which has the following properties:

(i) In period 1 the manager chooses the efficient effort level, such that $c^{\prime}\left(e_{1}{ }^{*}\right)=1$. He receives a wage $w_{1}=E[a]+e_{1}^{*}$.

(ii) In period 2 the manager receives a wage $w_{2}=y_{1}-e_{1}{ }^{*}$ and exerts no effort.

A rational worker chooses a high effort level in the first period to suggest a high ability to the labour market. In equilibrium, however, he does not succeed to deceive the labour market, as his behaviour is anticipated by the potential employers. Nonetheless, the manager cannot escape from this logic. A lower effort level in the first period would make the labour market believe that he is of lower ability and, hence, he would get lower wage offers in the second period.

\subsection{The Revealed Ability Setting}

In this setting it is very simple to solve for the equilibrium. Analogously to the previous section the manager never has any interest in exerting positive effort in period 2 . The game stops afterwards and hence, he cannot gain anything from increasing his output. Again the value of a manager in the second period is only determined by his ability. In this setting, all firms perfectly know the manager's ability before they make their second period wage offers. The bidding process leads to Bertrand competition among firms. In equilibrium the offered wage exactly corresponds to the manager's ability

$$
w_{2}=a \text {. }
$$

Otherwise a firm, whose wage offer is not accepted by the agent, can raise its offer and still make a positive profit. In this case the manager cannot gain anything by exerting a positive effort level in period 1 since he is not able to affect the firms' beliefs on his ability. It follows that the first period value of the manager to all firms is simply the expected value of his ability and therefore it must hold in equilibrium that

$$
w_{1}=E[a]
$$

We can summarise those considerations in the following result: 


\section{Theoretical Result 2: (Revealed Ability Setting)}

The unique perfect Bayesian equilibrium in pure strategies has the following properties:

(i) The manager does not exert any effort in both periods.

(ii) In period 1 the manager receives a wage equal to his expected ability $w_{1}=E[a]$ in the second period the wage is equal to his ability $w_{2}=a$.

\subsection{Summary of Predictions Based on the Theoretical Model}

As we have seen in the preceding sections, the model yields an unambiguous prediction: In the hidden ability setting we should expect high effort levels in the first period. In contrast, in the revealed ability treatment the theoretical model predicts no effort at all. Hence, in theory it is exactly the fact that the composition of outputs is not transparent which leads to high equilibrium efforts in the first period. The manager is unable to affect the market's beliefs on his ability with a higher effort level. Therefore, in theory transparency destroys effort incentives. It is this prediction that we want to analyse empirically.

Note that these results remain unchanged qualitatively when participants are risk averse. Riskaverse firms will simply make lower wage offers in period one in both settings, as their return is uncertain. Wage offers in period 2 are unaffected by the firms' risk preferences in both settings. In the revealed ability setting there is no risk since second period returns are always perfectly known. In the hidden ability setting returns are also perfectly known in equilibrium because firms can precisely infer the managers' ability. In both settings managers' risk aversion does not alter the results. In any case the managers do not exert any effort when abilities are revealed. In the hidden ability setting, although the manager's return in period 2 is uncertain, his expected utility is still maximised when $c^{\prime}\left(e_{1}{ }^{*}\right)=1$.

\section{Experimental Design}

The experiment is based on the model described above but for a more natural representation of a labour market we implemented three managers on the one side and four firms on the other side of the market. We chose a cost function ${ }^{4}$ such that equilibrium effort in the first period was equal to 12 . For the chosen distribution of abilities the the existence of the pure strategy equilibrium in the hidden ability treatment is assured.

4 The cost function as presented to the participants can be found in the Appendix. Note that marginal cost of effort less than 12 is less than 1 and marginal cost of effort higher than 12 is higher than 1. 
Table 1 : Experimental Design

\begin{tabular}{lcc}
\hline \hline & Hidden ability & Revealed ability \\
\# independent observations & 6 & 7 \\
Information revealed after first period & output & output, ability \\
Equilibrium effort in period 1 & 12 & 0 \\
Equilibrium effort in period 2 & 0 & 0 \\
Initial capital balance of managers & \multicolumn{2}{c}{100} \\
Initial capital balance of firms & 150 \\
\# rounds per session & $\{0, \ldots, 19\}$ \\
Integer set of abilities & $\{0, \ldots, 38\}$ \\
Integer set of wages & $\{0, \ldots, 19\}$ \\
Integer set of efforts & \\
\hline \hline
\end{tabular}

The experiment was conducted in the Laboratorium für experimentelle Wirtschaftsforschung $(e L a b)$ at the University of Erfurt. 112 students participated in total - most of whom were enrolled in the Faculty of Law, Economics, and the Social Sciences. Two treatments were implemented according to the two settings analysed in the preceding section (see Table 1). For both treatments - the hidden ability treatment and the revealed ability treatment - we conducted four sessions with 14 participants each. A session consisted of 12 identical rounds and lasted for about 2 hours. During the session payoffs were given in our fictitious experimental currency "Taler". After a session payoffs were converted to DM and paid in cash with an exchange rate of $0.1 \mathrm{DM}(\approx 0.051$ Euro) for 1 Taler.

In the beginning the instructions were handed out and read aloud by the experimenter. Additionally, the participants were instructed how to use the experimental software. ${ }^{5}$ In order to reduce the influence of uncontrollable connotations the strategic situation of the experiment was presented in completely neutral terms. Terms like "employer" or "employee" were avoided, instead the roles were referred to as players of type A (managers) and type B (firms). We spoke of "transfers" instead of "wages", the unknown ability was termed "basic value" and instead of "effort" a "number" could be selected.

After this all participants were seated in cubicles. The assignment of subjects to cubicles was done by drawing cards. The computer software matched participants randomly and anonymously into two equally sized groups. Three participants were assigned the role of a manager and four were assigned the role of a firm. Groups and roles were fixed during the

5 A translation of the instruction sheet can be found in the appendix. The experimental software was developed by making use of the toolbox zTree (Fischbacher 1998). 
whole experiment. Thus, we could collect two independent observations per session. ${ }^{6}$ Communication - other than through the experimental software - was not allowed. In the beginning of each round every manager was assigned a new ability which, however, was not disclosed. In order to facilitate a comparison of groups and treatments we implemented in all groups the same sequence of abilities which we randomly determined before the experiment. One round consisted of two periods. In the beginning of a period the four firms simultaneously had to make wage offers for each of the three managers. Afterwards a manager could choose to accept one of his four offers or to reject all of them. In case of a rejection the period ended for the respective manager. If the manager accepted an offer the wage was immediately transferred. Note that more than one manager could be employed by a single firm.

After the wage payment the manager had to choose his effort and to bear the cost associated with his choice. The employer whose offer was accepted received the output, i.e. the sum of effort and ability. In both treatments the output was also communicated to the employee. This enabled him to easily derive his own ability after the first period. The structure of the second period was identical to that of the first period. However, the amount of information available to the employers was different when they had to make their offers. Whereas employers did not know anything about the managers except the distribution of abilities when they formulated their offers for the first period, information was provided before the second period. In the hidden ability treatment an employer was informed about the first period output of each manager. In the revealed ability treatment, additionally, the ability of each manager was disclosed before the second period. Given this information the employers could specify their wage offers for the second period. It is worth mentioning that the order of the screen presentation for the players was fixed only for one round. It was made very clear to the participants that after each round the order was reshuffled randomly. Thus, identification of players over rounds was not possible.

6 Unfortunately, we lost two observations in the hidden ability treatment and one in the revealed ability treatment due to computer problems in one session. In two other sessions we had to fill vacancies with people who were familiar with the strategic background of the experiment because some students did not show up although they were registered. 


\section{Results}

We start by reporting our main experimental results for the two treatments. Then, we outline the differences between behaviour in both settings and provide possible explanations. All of our non parametric statistical tests preserve the independence of observations.

\subsection{The Hidden Ability Treatment}

When analysing the behaviour of the experimental subjects there is some evidence for the importance of career concerns in the sense of Holmström's model: Within the hidden ability treatment average effort levels are significantly higher in period 1 than in period $2(\alpha=10 \%$, Wilcoxon signed rank test, two-tailed).

\section{Experimental Result 1: (Hidden Ability Treatment)}

Effort is higher in period 1 than in period 2.

According to the theoretical model effort should be higher in period 1 than in period 2 because the agent can affect the market's beliefs about his ability in the second period by choosing a high effort level in the first period. The potential employers should infer from a high output in the first period a high ability and, hence, offer higher second period wages. Therefore, one may expect that high first period outputs go along with high second period wage offers. To test for such causality we perform a linear regression with second period wage as the dependent variable, which is explained by the output in the first period. The results of the regression with robust standard errors are summarized in Table 2. As the analysis of the theoretical model already suggests, the output 1 coefficient is positive $(0.378)$ and statistically significant $(p<0.05)$. Although the coefficient is far from being equal to $1-$ as predicted by theory - this observation indicates a career concerns effect: on average firms offer higher wages to a manager in period 2 , the higher his output was in period 1 . Hence, it is indeed beneficial for the agent to raise his effort level above zero. 
Table 2 : Output1-wage2 relation (dependent variable: wage in period 2)

\begin{tabular}{lcc}
\hline \hline & Hidden Ability Treatment & Revealed Ability Treatment \\
\cline { 2 - 3 } Output 1 & $0.378^{* *}$ & \\
& $(0.135)$ & $0.851^{* * *}$ \\
Ability & & $(0.119)$ \\
& & $0.319^{* * *}$ \\
Effort 1 & & $(0.087)$ \\
& & $3.590^{* * *}$ \\
Constant & $(1.321)$ & $(0.907)$ \\
& $N=194 * *$ & $N=237$ \\
& $p=0.038$ & $p=0.000$ \\
\hline \hline
\end{tabular}

Note: Numbers in parentheses are robust standard errors. ***,**,* denote significance at the $1 \%, 5 \%$ - and $10 \%$ level, respectively.

Although we observe a positive effect of first period output (= ability + first period effort) on second period wages, first period effort levels are much lower than theory predicts. The average effort level is 3.54. It is well below the predicted 12 for all six independent observations. Accordingly, the hypothesis that effort levels attain the theoretical prediction can clearly be rejected ( $\alpha=5 \%$, Wilcoxon signed rank test, two-tailed). Second period effort levels are 2.52 on average which is much higher than the theoretically predicted zero effort. Figure 1 shows the average effort levels in periods 1 and 2 for the twelve rounds in both treatments.
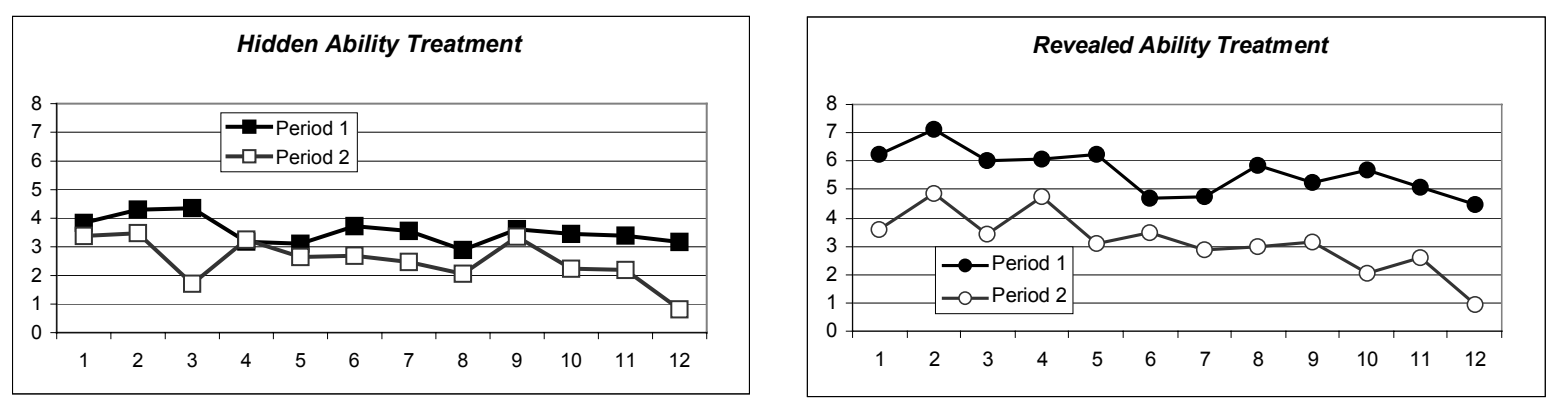

Figure 1: Average effort levels in both treatments over all rounds

Cumulative distribution functions of effort choices are shown in Figure 2. It is evident that the theoretical prediction in the hidden ability treatment in period 1 (effort choice 12) is barely confirmed, whereas more than 50 percent of all effort choices are consistent with the theoretical prediction in period 2 (effort choice 0). Nevertheless, a substantial number of effort choices in period 2 are positive. The observed willingness to exert non-zero effort in period 2 may be explained by reciprocity motives since strategic considerations do not play a role in the last stage. 

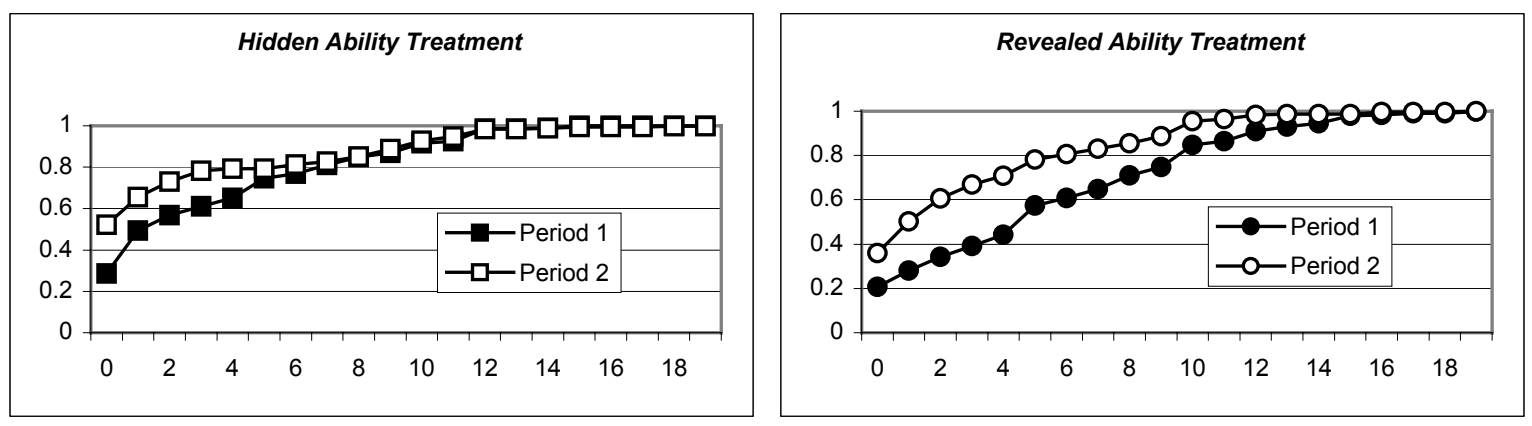

Figure 2: Cumulative distribution functions of effort choices

To obtain some insight in how the willingness to exert effort is influenced by the size of the wages offered, we perform linear regressions with effort as the dependent variable explained by the wage in the same period. Table 3 und Table 4 contain the results of regressions with robust standard errors in period 1 and period 2 respectively. The wage coefficients are positive in both periods (period 1: 0.220 and period 2: 0.217 ) and statistically highly significant $(p<0.01)$. This indicates that on average in both periods, managers provide higher effort levels, the higher the wages paid to them. ${ }^{7}$

Table 3 : The wage-effort relation in period 1 (dependent variable: effort in period 1)

\begin{tabular}{lcc} 
& Hidden Ability Treatment & Revealed Ability Treatment \\
\cline { 2 - 3 } Wage 1 & $0.220^{* * *}$ & $0.172^{* * *}$ \\
& $(0.040)$ & $(0.038)$ \\
Constant & 0.725 & $2.724^{* * *}$ \\
& $(1.254)$ & $(0.666)$ \\
\cline { 2 - 3 } & $N=194$ & $N=237$ \\
& $p=0.003$ & $p=0.004$ \\
\hline \hline
\end{tabular}

Note: Numbers in parentheses are robust standard errors. $* * *, * *, *$ denote significance at the $1 \%, 5 \%$ - and $10 \%$ level, respectively.

\footnotetext{
${ }^{7}$ The Spearman rank correlation coefficients between wages and effort computed separately for each round are also positive for almost all rounds in both periods (see Irlenbusch and Sliwka, forthcoming, which contains some further analysis of the hidden ability treatment but does not deal with the revealed ability treatment).
} 
Table 4: The wage-effort relation in period 2 (dependent variable: effort in period 2)

\begin{tabular}{ccc} 
& Hidden Ability Treatment & Revealed Ability Treatment \\
\cline { 2 - 3 } Wage 2 & $0.217 * * *$ & $0.182^{* *}$ \\
& $(0.051)$ & $(0.064)$ \\
Constant & -0.357 & 0.553 \\
& $(0.855)$ & $(1.071)$ \\
\cline { 2 - 3 } & $N=194$ & $N=237$ \\
& $p=0.008$ & $p=0.030$ \\
\hline \hline
\end{tabular}

Note: Numbers in parentheses are robust standard errors. $* * *, * *, *$ denote significance at the $1 \%, 5 \%$ - and $10 \%$ level, respectively.

\subsection{The Revealed Ability Treatment}

Surprisingly, also in the revealed ability treatment effort levels are higher in period 1 than in period 2 (see Figure 1). Whereas the average effort level in period 1 is 5.60 , in period 2 it is 3.14. This difference is significant ( $\alpha=5 \%$ Wilcoxon signed rank test, two-tailed).

\section{Experimental Result 2: (Revealed Ability Treatment)}

Effort is higher in period 1 than in period 2.

Even if ability is revealed to potential employers at the beginning of period 2 there seems to be a career concerns effect which is quite surprising from the viewpoint of the theoretical model. Thus, the question arises whether first period effort has an influence on second period wage in the revealed ability treatment. To examine this question we perform a linear regression with second period wage as the dependent variable, now explained by two variables: first period effort and ability. To differentiate between these two explaining variables appears to be appropriate because in the revealed ability treatment firms can perfectly distinguish between effort and ability when making second period wage offers. Table 2 contains the corresponding coefficients obtained from the regression with robust standard errors. It turns out that both coefficients are positive (ability: 0.851 and effort 1: $0.319)$ and highly significant $(p<0.01)$. Note that from a theoretical point of view the coefficient for ability should be 1 since firms know for sure that they earn a profit of the size of the manager's ability. The coefficient for effort 1 should be 0 because firms cannot expect 
any effort in period 2. Thus, the observed influence of first period effort on second period wage is surprisingly high. ${ }^{8}$

Effort choices in both periods differ substantially from the prediction made by the subgame perfect equilibrium. Again the observed non-zero effort choices might be due to motivations exhibited by the managers to respond reciprocally to wages. Table 3 und Table 4 contain the results of regressions with robust standard errors with effort as the dependent variable explained by the wage in the same period. Similar to the hidden ability treatment also in the revealed ability treatment the wage coefficients are positive in both periods (period 1: 0.172 and period 2: 0.182). Thus, we conclude that also in the treatment with revealed abilities managers tend to increase their effort choices if firms offer higher wages.

However, quite important and in stark contrast to the theoretical prediction, the difference in effort levels across both periods appears to be unambiguously stronger in the revealed ability treatment than in the hidden ability treatment! As this observation is quite interesting and very surprising we will analyse it more closely in the subsequent section.

\subsection{A Comparison of both Treatments}

Indeed, there is not only a high first period effort - averaged over rounds - in the revealed ability treatment, in addition this average effort is significantly higher than the average effort in the hidden ability treatment ( $\alpha=10 \%$, Mann-Whitney-U test, two-tailed).

\section{Experimental Result 3:}

In the revealed ability treatment first period effort is higher than in the hidden ability treatment.

Figure 1 shows the average first period effort over time in both treatments. Observed behaviour is exactly opposite to the theoretical prediction. In the revealed ability treatment where - according to theory - there should be no career concerns at all, apparently we observe even stronger incentives to exert effort in the first period than in the hidden ability treatment. This result is also reflected in Figure 2: about 50 percent of all effort choices in period 1 are equal to or less than 1 in the hidden ability treatment while in the revealed ability treatment 0 and 1 are chosen in about 25 percent of the effort choices in period 1.

\footnotetext{
${ }^{8}$ A linear regression with (wage 2 - ability) as the dependent variable explained by first period effort, yields a similar influence of first period effort, i.e. the coefficient for effort 1 is equal to 0.309 .
} 
One might conjecture that the degree to which managers act reciprocally also within a period could explain why effort in period 1 is lower in the hidden ability treatment than in the revealed ability treatment. In fact it is known from the ultimatum game literature (Mitzkewitz and Nagel 1993; Güth, Huck, and Ockenfels 1996; Kagel, Kim, and Moser 1996; Huck 1999) that under asymmetric information behaviour becomes more selfish. A potential rationale is that firms pay lower wages in the hidden ability treatment - which, however, is not significant, compare Table 5 - because they expect less effort since there is the possibility of hiding behind a low ability. A comparison of the coefficients contained in Table 3 reveals that the observed higher first period effort in the revealed ability treatment is unlikely to be due to more pronounced reciprocal reactions: the coefficients which express the influence of first period wage on effort are similar in both treatments. Instead the constant is much higher in the revealed ability treatment. In order to provide a more robust statistical test for this observation, we computed simple linear regressions for each independent observation to explain the effort exerted in a period by the received wage in the same period. The slope with respect to wage measures the direct reciprocity of the agent as it yields an estimate for the additional effort exerted per unit of wage. The constant term in each regression measures the agent's unconditional willingness to exert effort, which does not depend on the received wage. A nonparametric comparison of those measures yielded no significant difference between the two treatments except for the constant term in the first period: the constant terms for the first period are significantly higher in the revealed ability treatment $(\alpha=5 \%$, Mann Whitney U-Test, one-tailed).

In both treatments the wage in period 2 is influenced by the output in period 1. Firms in the revealed ability treatment can distinguish between the ability and the period 1 effort, which are the two components of the period 1 output. However, this is not possible in the hidden ability treatment. A comparison of the two regressions contained in Table 2 indicates that the effect of period 1 output in the hidden ability treatment on period 2 wage is similar to the effect of the period 1 effort on period 2 wage in the revealed ability treatment. However, in the revealed treatment the influence of ability on period 2 wage is much stronger. This is an interesting observation because it indicates that in the hidden treatment ability has a much weaker effect on second period wage than in the revealed treatment where as here it is directly observable. Note, however, that the constant of the output1-wage2 regression is much higher in the hidden than in the revealed ability treatment. Hence, on average the second period wage is more sensitive to the first period outcome in the revealed ability treatment. The latter is 
immediately visible from the trend lines in Figure 3 which shows all pairs of first period outputs and second period wages for both treatments.
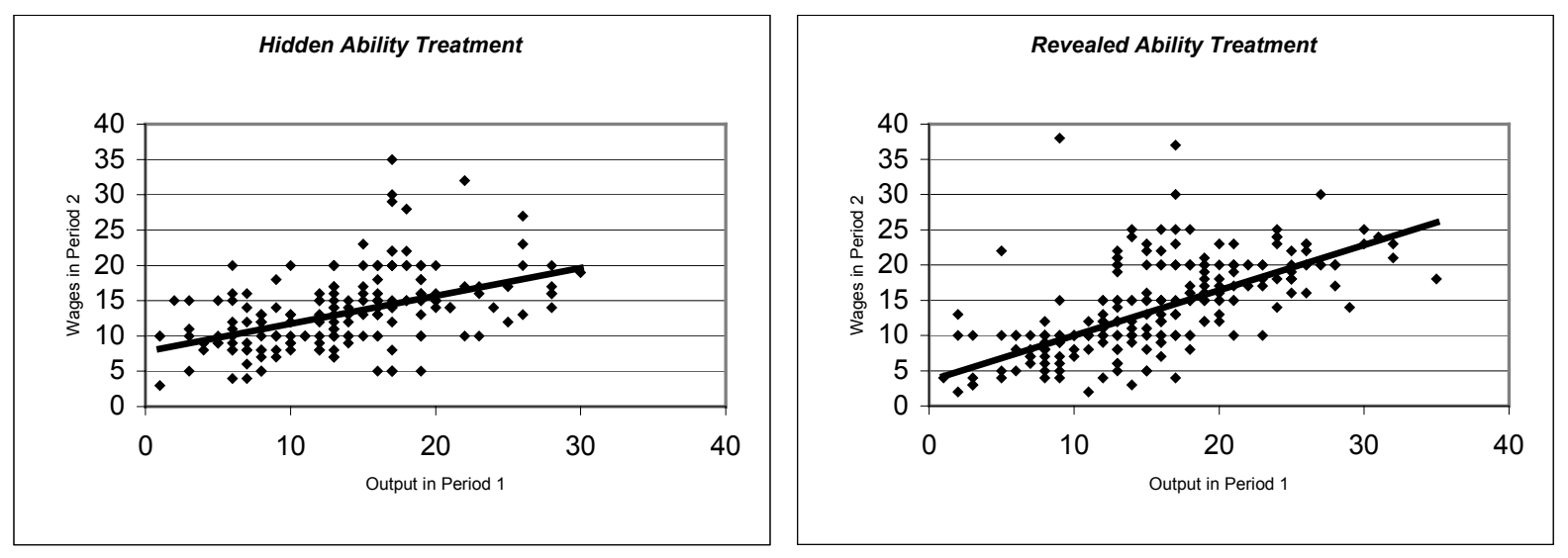

Figure 3: First period outputs and second period wages in both treatments

The following table summarises average values for efforts and wages for both treatments and both periods.

Table 5: Average wages and efforts

\begin{tabular}{lcc}
\hline \hline & Hidden ability treatment & Revealed ability treatment \\
Effort Period 1 & 3.54 & 5.60 \\
Effort Period 2 & 2.52 & 3.14 \\
Wage Period 1 & 13.56 & 15.62 \\
Wage Period 2 & 13.23 & 13.74 \\
\hline \hline
\end{tabular}

Before we discuss possible explanations, we will briefly state some other results. First, note that second period efforts seem to be slightly higher in the revealed ability treatment than in the hidden ability treatment, but this relation is not significant $(p=0.45$, Whitney-Mann-U test, two-tailed). The same is true for first period wages ( $p=0.23$, Whitney-Mann-U test, twotailed). In addition, it is interesting to look at the profits of both types of players to understand the structure of the stylised labour market considered in our setting. In Figure 4 the average profit of all firms are plotted for the 12 rounds for both treatments. Note that firms make profits close to zero in all treatments and periods. Recall, that firms had a weak position as there is always at least one firm left, which was not able to hire a manager. The theoretical prediction of Bertrand-like competition among firms for managers is well established. Firms do indeed bid up until they earn no profits. Furthermore, the fact that average profits are mainly negative indicates the relevance of a winner's curse effect: A firm that overestimates the output of a manager will win the competition and as a consequence will make losses. 

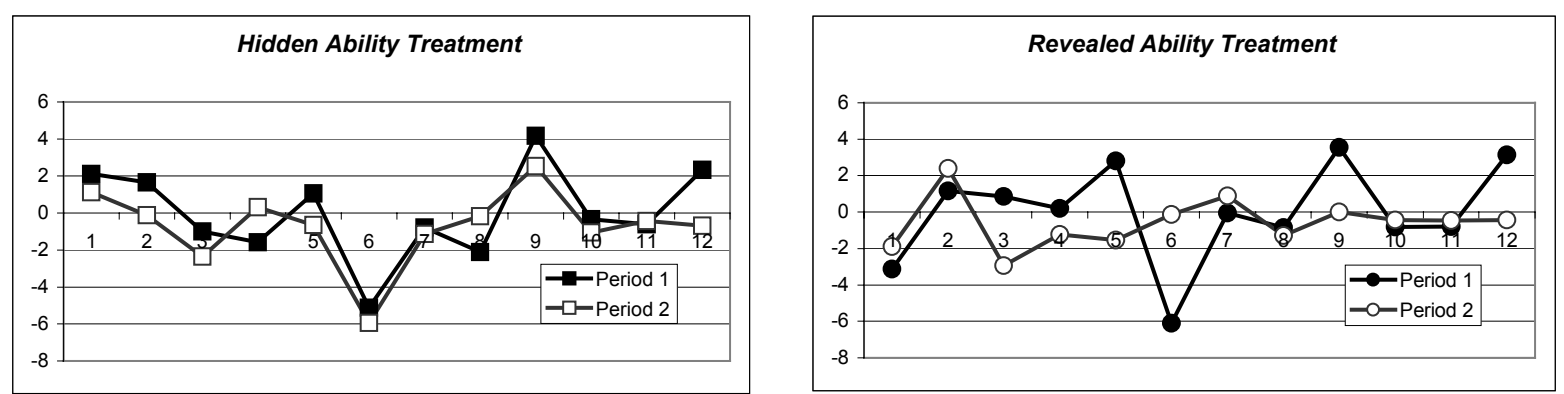

Figure 4: Average profit of firms in both treatments over all rounds

The movement over rounds in the structure of profits is due to the average values of the abilities drawn in each round. Therefore, the development of profits is very similar in both treatments, as the sequence of random abilities was the same in all sessions. Observe that peaks are smaller in the second period of the revealed ability treatment. In that treatment firms had more information as they perfectly knew the ability before the beginning of period 2 . Hence, their estimates of the "true" value of a manager are better and profits are closer to zero. An analogous effect is also present in the hidden ability treatment, which is confirmed by looking at the managers' profits. As can directly be seen from Figure 5, in the hidden ability treatment the profit curve is flatter in period 1 than in period 2. In period 1 the firm has no information and, hence, takes the whole risk which results from the uncertain ability of the manager. Due to the exact knowledge of the ability in period 2 this effect is stronger in the revealed ability treatment. Note, that - as theory predicts - the managers on the strong side of the market absorb all profits.
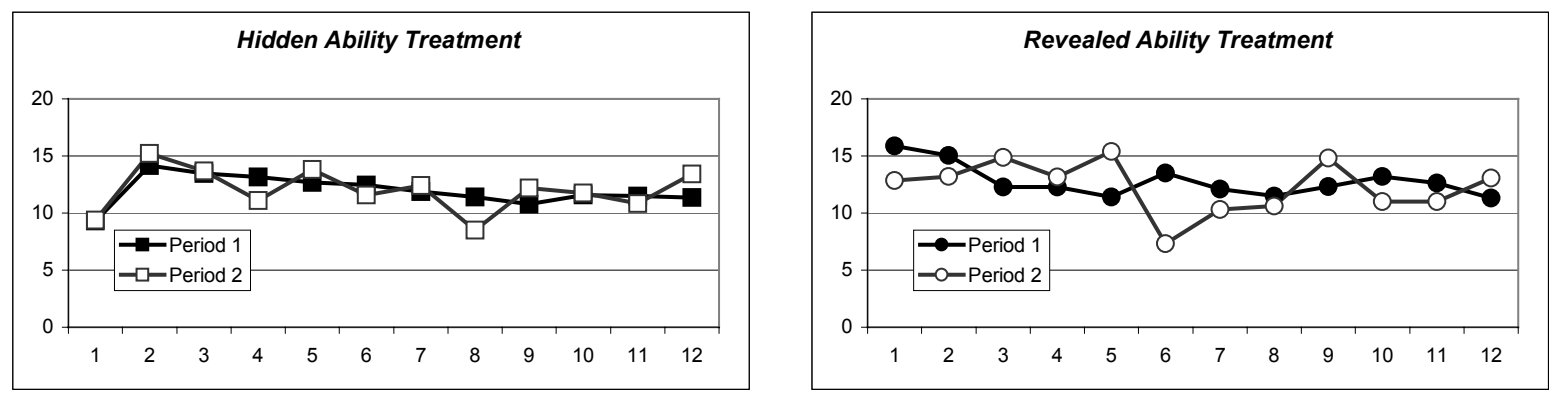

Figure 5: Average profit of managers in both treatments over all rounds

\section{Discussion}

We observe that there is also a career concerns effect in the revealed ability treatment. Although contradicting the theoretical prediction, this observation is in line with previous 
experimental findings. Indeed many experiments have shown that there is a certain share of subjects who behave fairly or reciprocally by investing effort after having received a positive wage even if the subgame perfect equilibrium predicts an effort level of zero (for excellent overviews, see Fehr and Gächter 2000, and Fehr and Schmidt, forthcoming). One explanation for the observed behaviour is that in the first period subjects want to signal their readiness to exert high effort. Someone who has not exerted a high effort in the first period will of course not be expected to exert a high effort in the second period. Therefore, high effort in the first period is a precondition for second period wage offers higher than ability. ${ }^{9}$ We conclude that with high outputs in the first period subjects not only try to signal a high ability, but also a high readiness to exert effort.

However, the important question arises why this effect is weaker in the hidden ability treatment than in the treatment where the ability is revealed after the first period. Although the situations in both treatments differ only in one feature - the visibility of ability -, strategically two things have changed: in the revealed ability treatment it is not possible to pretend a high ability by exerting higher effort, and there is the possibility to build a reputation for reciprocity or high effort. Whereas the former should lead managers to exert lower effort in the first period, the latter is likely to increase effort. In the hidden ability treatment raising the first period effort level may have a dual purpose as it should increase the market's beliefs on the manager's ability parameter as well as on his degree of reciprocity. However, in the experiment this does not lead to higher effort levels as one might conjecture. In contrast, the transparency in the revealed ability treatment raises effort levels. Transparency may have a positive effect in several respects in our experiment:

- Transparency makes it easier to pretend being a "Homo reciprocans" and to build a reputation for reciprocity: In the hidden ability treatment firms cannot distinguish between ability and effort and therefore cannot tell whether an agent behaves reciprocally in the first period or simply has a higher ability.

- Reciprocity may be stronger if it is directly perceived by the person with whom interaction takes place: In the revealed ability treatment reciprocity is directly perceived by the employers as they learn the effort of an agent perfectly after the first period. In the hidden ability treatment this is not the case, hence, managers might feel less inclined to act reciprocally as a bad output may be "excused" with the realization of a low (unknown) ability. 
- Signalling a high willingness to exert effort may be a more natural behavioural motive than exerting effort to make the market believe that one has a high ability parameter.

Some support to the first explanation - transparency should make it easier to signal reciprocal behaviour - is given in Irlenbusch and Sliwka (2003). In this paper a simple repeated gift exchange game is examined where the principal's revenue is determined by the agent's effort and a random component. A "transparent" situation in which principals can directly observe agents' efforts is compared with an "intransparent" one where they only observe total revenue. In a simple model it is shown theoretically that in an intransparent situation there are indeed smaller incentives for selfish agents to build a reputation for reciprocity. ${ }^{10}$ The experimental results of that paper show that reciprocal behaviour measured by the correlation between wages and efforts indeed declines when transparency is reduced. ${ }^{11}$ However, in the present experiment we do not find evidence for stronger direct reciprocity because the wage coefficients of our regressions explaining the effort in the same period (shown in Table 3 and Table 4) are of similar size in both treatments. Hence, we doubt that the first explanation is of high relevance for our results.

Furthermore, this observation also seems to cast some doubt on the relevance of the second explanation given. However, according to the estimated constant terms of the wage-effort regressions shown in Table 3, in period 1 the unconditional willingness to exert effort is substantially higher in the revealed ability treatment than in the hidden ability treatment. This observation strongly supports our third conjecture: Signalling a high willingness to exert effort may indeed be a more natural behavioural motive than exerting effort to make the market believe that one has a high ability parameter. Our results in the hidden ability treatment indicate that strategic "signal jamming" considerations play a much smaller role than theory suggests. But signalling a high willingness to exert effort is much easier in the revealed ability treatment where the effort is directly observed.

\footnotetext{
${ }^{10}$ A certain fraction of the population of agents is assumed to have Fehr-Schmidt-type utility functions and therefore those agents show some form of reciprocal behaviour. As those agents receive high wage offers in the future, there are some incentives for selfish types to imitate them.

${ }^{11}$ However, average effort levels did not differ significantly between both treatments as some individuals chose extremely high effort levels in the intransparent treatment - seemingly to ascertain that their respective principal understands for sure that they are indeed willing to exert high efforts.
} 


\section{Conclusion}

The experimental results shown in this paper help to clarify and extend the notion of career concerns. One implication of our analysis is that career concerns should be understood in a broader sense than the strategic motive of making the market believe in a higher ability parameter. Career concerns should encompass all considerations an agent makes that aim at increasing future wages and career perspectives.

In that broader sense our paper reinforces the importance of career concerns as an incentive device. First of all, in the treatment with hidden abilities as in Holmström's original model, we do observe efforts which are higher in the first than in the second period. But we also observe such behaviour in the revealed ability treatment, where no such thing should happen from the theoretical perspective. Surprisingly, in the latter setting this effect is even stronger. Hence, in environments in which the ability signal jamming mechanism cannot work career concerns do play an even stronger role in generating incentives. Economic agents exert higher efforts in the beginning of their career because that leads to higher wage offers in the future. As we have observed, their motivation to do so is higher when their efforts are directly observed.

This result has an important implication. In the spirit of Holmström's model transparency is detrimental as it destroys incentives: Only if the market cannot tell whether a good performance is due to a high ability or a high effort, a manager will work hard to demonstrate high ability. Our observation, however, points in the opposite direction. Only if the market can distinguish effort and ability a manager has the opportunity to demonstrate his willingness to exert high effort. As we have seen, the latter is a more important behavioural motive and hence, leads to higher effort levels. We conclude that transparency does not weaken, but on the contrary strengthens the incentive generating force of career concerns. 


\section{References}

Abbink, K., Irlenbusch, B., Renner, E. (2000) “The Moonlighting Game - An Experimental Study on Reciprocity and Retribution" Journal of Economic Behavior and Organization $42(2), 265-277$.

Andersson, F. (2002) "Career Concerns, Contracts, and Effort Distortions" Journal of Labor Economics 20 (1), 42-58.

Auriol, E., Friebel, G., Pechlivanos, L. (2002) "Career Concerns in Teams" Journal of Labor Economics 20(2), 289-307.

Bénabou, R., Tirole, J. (2002): Intrinsic and Extrinsic Motivation. Mimeo IDEI Toulouse.

Berg, J., Dickhaut, J., McCabe K. (1995) “Trust, Reciprocity and Social History”, Games and Economic Behavior 10, 122-142

Charness, G. (1998) "Attribution and Reciprocity in a simulated labor market: an experimental investigation", Discussion Paper, UPF Barcelona.

Clark, K., Sefton M. (2001) "The Sequential Prisoner's Dilemma: Evidence on Reciprocation", Economic Journal 111, 51-68.

Dewatripont, M., Jewitt, I., Tirole, J. (1999a) "The Economics of Career Concerns, Part I: Comparing Information Structures”, Review of Economic Studies 66: 183-198.

Dewatripont, M., Jewitt, I., Tirole, J. (1999b) "The Economics of Career Concerns, Part II: Application to Missions and Accountability of Government Agencies", Review of Economic Studies 66: 199-207.

Dufwenberg, M., Gneezy, U. (2000) "Measuring Beliefs in an Experimental Lost Wallet Game", Games and Economic Behavior 30, 163-182.

Dufwenberg, M., Kirchsteiger, G. (2000) "Reciprocity and Wage Undercutting", European Economic Review 44, 1069-1078.

Fama, E. F. (1980), "Agency Problems and the Theory of the Firm", Journal of Political Economy 88: 288-307.

Fehr, E., Gächter, S., Kirchsteiger, G. (1997) "Reciprocity as a Contract Enforcement Device - Experimental Evidence", Econometrica 64, 833-860.

Fehr, E., Gächter, S. (2000) “Fairness and Retaliation: The Economics of Reciprocity”, Journal of Economic Perspectives 14 (3), 159-181.

Fehr, E., Kirchsteiger, G., Riedl, A. (1993) "Does Fairness prevent Market Clearing? An Experimental Investigation”, Quarterly Journal of Economics 108 (2), 437-460.

Fehr, E., Klein, A., Schmidt, K. (2002) "Fairness, Incentives, and Contractual Incompleteness", Mimeo, University of Munich. 
Fehr, E., Schmidt, K. (2000) "Fairness, Incentives and Contractual Choices", European Economic Review 44, 1057-1068.

Fehr, E., Schmidt, K. (forthcoming) "Theories of Fairness and Reciprocity - Evidence and Economic Applications", to appear in: Dewatripont, M. et.al., Advances in Economic Theory, $8^{\text {th }}$ World Congress of the Econometric Society.

Fischbacher, U. (1998) "Z-Tree: A Toolbox for Readymade Economic Experiments" University of Zurich

Gächter, S., Falk, A. (2002) "Reputation and Reciprocity: Consequences for the Labor Relation", Scandinavian Journal of Economics 104, 1-26.

Gibbons, R., Murphy, K. (1992) "Optimal Incentive Contracts in the Presence of Career Concerns: Theory and Evidence", Journal of Political Economy 100, 468-505.

Gibbons, R., Waldman, M. (1999) "Careers in Organizations: Theory and Evidence", in: Ashenfelter, O. and Card, D. (eds), Handbook of Labor Economics, Vol. 3, NorthHolland, Amsterdam.

Güth, W., Huck, S., Ockenfels, P. (1996) "Two-level ultimatum bargaining with incomplete information", Economic Journal 106, 593-604.

Holmström, B. (1982) "Managerial Incentive Problems - A Dynamic Perspective", in: Essays in Economics and Management in Honor of Lars Wahlbeck, Helsinki; reprinted in: Review of Economic Studies 66, January 1999, 169-82.

Huck, S. (1999) "Responder behavior in ultimatum offer games with incomplete information", Journal of Economic Psychology 20, 183-206.

Irlenbusch, B., Sliwka, D. (2003) "Reciprocity and Effort Transparency", Discussion Paper University of Bonn and University of Erfurt.

Irlenbusch, B., Sliwka, D., "Zu impliziten Anreizen in Arbeitsbeziehungen - eine experimentelle Studie“, forthcoming in: Zeitschrift für Betriebswirtschaft.

Kagel, J., Kim, C. K., Moser D. (1996) "Fairness in ultimatum games with asymmetric information and asymmetric payoffs", Games and Economic Behavior 13, 100-110.

Mitzkewitz, M., Nagel, R. (1993) "Experimental Results on Ultimatum Games with Incomplete Information", International Journal of Game Theory 22, 171-198.

Van der Heijden, E., Nelissen, J. Potters, J., Verbon, H. (2001) "Simple and Complex Gift Exchange in the Laboratory" Economic Inquiry 39, 280-297. 


\section{Appendix: Equilibrium in the Hidden Ability Setting}

First, we have to compute $E\left[w_{2}\left(y_{1}\right) \mid e_{1}\right]$, which is given by

$$
\begin{aligned}
E\left[w_{2}\left(a+e_{1}\right) \mid e_{1}\right] & =P\left(a+e_{1}<e_{1}^{*}\right) 0+E\left[\left(a+e_{1}-e_{1}^{*}\right) \cdot I_{\left\{e_{1}^{*} \leq a+e_{1} \leq e_{1}^{*}+A\right\}}\right]+P\left(a+e_{1}>e_{1}^{*}+A\right) A \\
& =E\left[\left(a+e_{1}-e_{1}^{*}\right) \cdot I_{\left\{e_{1}^{*}-e_{1} \leq a \leq e_{1}^{*}-e_{1}+A\right\}}\right]+P\left(a>e_{1}^{*}-e_{1}+A\right) \cdot A,
\end{aligned}
$$

where $I$ is the indicator function. When $e_{1}<e_{1}^{*}-A$ this must be 0 , for $e_{1}^{*}-A<e_{1}<e_{1}^{*}$ it is equal to

$$
\int_{e_{1}^{*}-e_{1}}^{A}\left(a+e_{1}-e_{1}^{*}\right) \frac{1}{A} d a=\frac{A}{2}+e_{1}-e_{1}^{*}+\frac{1}{2 A}\left(e_{1}-e_{1}^{*}\right)^{2} .
$$

If, however, $e_{1}^{*} \leq e_{1} \leq e_{1}^{*}+A$ it is

$$
\int_{0}^{e_{1}^{*}-e+A}\left(a+e_{1}-e_{1}^{*}\right) \frac{1}{A} d a+\frac{e_{1}-e_{1}^{*}}{A} A=\frac{\left(e_{1}-e_{1}^{*}+A\right)\left(e_{1}^{*}-e_{1}+A\right)}{2 A}+e_{1}-e_{1}^{*} .
$$

And finally for $e_{1}>e_{1}^{*}+A$ it is equal to $A$. By taking the first derivative of the expressions we get that

$$
\frac{\partial E\left[w_{2}\left(a+e_{1}\right) \mid e_{1}\right]}{\partial e_{1}}= \begin{cases}0 & \text { if } e_{1}<e_{1}^{*}-A, \\ 1+\frac{e_{1}-e_{1}^{*}}{A} & \text { if } e_{1}^{*}-A \leq e_{1}<e_{1}^{*}, \\ 1-\frac{e_{1}-e_{1}^{*}}{A} & \text { if } e_{1}^{*} \leq e_{1} \leq e_{1}^{*}+A, \\ 0 & \text { if } e_{1}>e_{1}^{*}+A .\end{cases}
$$

Note that $E\left[w_{2}\left(y_{1}\right) \mid e_{1}\right]$ is continuously differentiable. A necessary condition for $e_{1}^{*}$ to be an equilibrium is now that $\left.\frac{\partial E\left[w_{2}\left(a+e_{1}\right) \mid e_{1}\right]}{\partial e_{1}}\right|_{e_{1}=e_{1}^{*}}=c^{\prime}\left(e_{1}^{*}\right)$ which is equivalent to $c^{\prime}\left(e_{1}^{*}\right)=1$. Note, however, that $E\left[w_{2}\left(y_{1}\right) \mid e_{1}\right]$ is only concave for $e_{1} \geq e_{1}^{*}$. Hence, the first order condition is not sufficient for an optimal decision by the agent. A sufficient condition for $e_{1}^{*}$ to be optimal is that $\frac{\partial E\left[w_{2}\left(a+e_{1}\right) \mid e_{1}\right]}{\partial e_{1}} \geq c^{\prime}\left(e_{1}\right)$ for all $e_{1} \leq e_{1}^{*}$ or

$$
1+\frac{e_{1}-e_{1}^{*}}{A} \geq c^{\prime}\left(e_{1}\right) \text { for all } e_{1} \leq e_{1}^{*}
$$

This condition is satisfied if $A$ is sufficiently large because $c^{\prime}\left(e_{1}\right)<1$ if $e_{1} \leq e_{1}^{*}$. In particular, for quadratic cost functions $c(e)=\frac{c}{2} e^{2}$ we have $e_{1}^{*}=\frac{1}{c}$ and this condition is equivalent to

$$
1+\frac{e_{1}-\frac{1}{c}}{A} \geq c e_{1} \Leftrightarrow(A c-1) \frac{1}{c} \geq(A c-1) e_{1}
$$

for all $e_{1} \leq e_{1}^{*}=\frac{1}{c}$ which holds whenever $A \geq e_{1}^{*}=\frac{1}{c}$. 
Appendix: Presentation of the Cost Function as Provided to the Participants

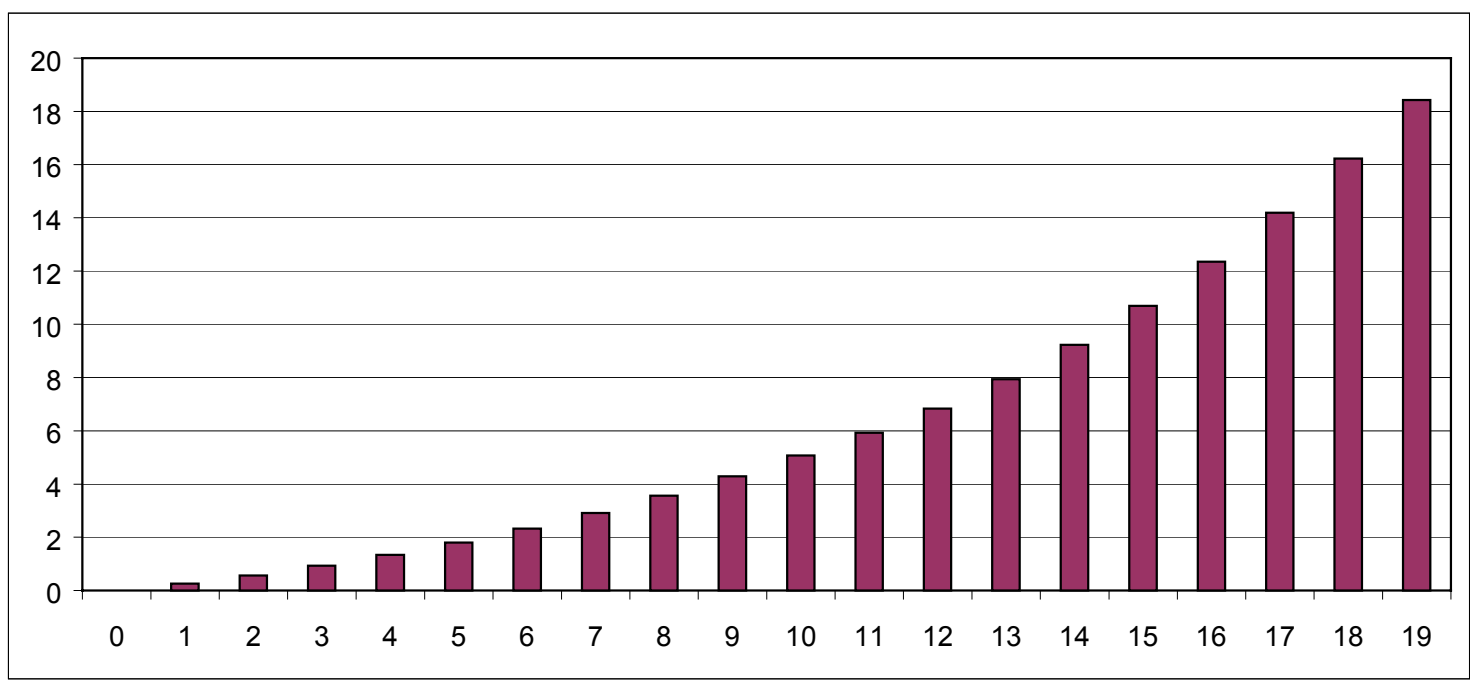

\begin{tabular}{|c|c|c|c|c|c|c|c|c|c|c|}
\hline Number & 0 & 1 & 2 & 3 & 4 & 5 & 6 & 7 & 8 & 9 \\
\hline Cost & 0.00 & 0.26 & 0.57 & 0.93 & 1.34 & 1.80 & 2.33 & 2.92 & 3.57 & 4.29 \\
\hline Number & 10 & 11 & 12 & 13 & 14 & 15 & 16 & 17 & 18 & 19 \\
\hline Cost & 5.08 & 5.93 & 6.84 & 7.94 & 9.23 & 10.70 & 12.35 & 14.19 & 16.22 & 18.43 \\
\hline
\end{tabular}




\section{Appendix: Experimental Instructions}

(original instructions were in German; they are available upon request from the authors; treatment differences in instructions are indicated by hidden ability treatment. "..."; revealed ability treatment. “..."\})

\section{Rounds, Periods and Roles}

- The experiment consists of 12 rounds - each comprising 2 periods

- During the experiment you belong to a group of 7 members including yourself. Each player belongs to one of the two groups but nobody knows the identity of the other six members. The composition of the groups does not change throughout the experiment.

- There are two different roles, type A-players and type B-players. There are four players of type A and three players of type B in each group. The different types are assigned at random in the beginning and do not change during the experiment.

\section{The Basic Value}

At the beginning of each round, a new basic value is fixed for every player of type $B$. The basic values remain unknown during the whole experiment, i.e. they are not revealed to any of the players - not even to the players of type B themselves. It is only common knowledge that the basic values are chosen at random out of the set of integer numbers $\{0,1, \ldots 19\}$, each number being drawn with the same probability. The basic values are kept constant for the two periods. New basic values are selected in each new round.

\section{The Structure of a Period:}

\section{- Offer of transfer payments by the players of type A}

At the beginning of each period, every player of type A announces a certain amount of the fictitious currency "Taler" out of $\{0,1, \ldots, 38\}$ for each of the 3 players of type $B$ in his group and a direction in which he wants the amount to be transferred: either from him to the specific player $B$ or vice versa.

\section{- Acceptance or rejection of the transfer payment offer by the players of type B}

Each of the players of type $B$ decides whether he wants to accept one of the four offers proposed to him by the players of type $A$.

- In case he rejects all offers, his current period ends.

- In case he accepts one offer, the offered transfer occurs immediately, i.e. the amount of "Taler" is transferred from the account of the payer to that of the payee.

\section{- Selection of a number by the players of type $B$}

If a player of type B has accepted an offer by one of the players of type A - and the transfer of Taler has occurred - then this player of type $B$ has to select a number out of the integer set 
$\{0,1, \ldots, 19\}$. The larger the chosen number is, the more costs the type B-player has to pay (s. table of costs).

After the selection of this number, its costs are subtracted from the account of the very type Bplayer. The so-called result is calculated as follows: result $=$ selected number + basic value of this very type B-player. This result is added on the account of the type A-player whose offer has been accepted. Note that the type B-player only has to pay the costs of his selected number. The basic value causes no costs.

\section{Difference between the first and second period}

The procedure of both periods in a round is identical. But there is a difference in the information available to type A-players when they make their offers of transfer payments for type B-players. At the beginning of the first period, there is no information on the type B-players. However, before the second period, for each type B-player who had accepted an offer the \{hidden ability treatment. "transfer payment and the result"; revealed ability treatment. "transfer payment, base value, and the result" $\}$ are revealed. If he had rejected all offers this is also announced.

\section{Order of Appearance of the players}

During one round, the order of appearance of the players is kept constant, i.e. the player's position in the list of all players of his type is always the same in this very round. Before a new round starts, a new order is chosen at random. Consequently, it is impossible to recognise a player in different rounds by his position in the lists shown on the screen.

\section{Initial Capital and Total Payoffs}

At the beginning of the experiment, every participant gets a certain amount of initial capital in the fictitious currency Taler on his account. At the end of the experiment, his account will be changed into DM at an exchange rate of 0,10 DM per Taler and will be paid to the player.

\section{Please note:}

- During the experiment no communication is permitted - except via the experimental software.

- All decisions are made anonymously, i.e. no one gets to know the identity of someone else who has made a certain decision.

- In addition the final payment is made anonymously, i.e. no one learns how much another participant has earned. 


\section{IZA Discussion Papers}

\begin{tabular}{|c|c|c|c|c|}
\hline No. & Author(s) & Title & Area & Date \\
\hline 841 & $\begin{array}{l}\text { B. H. Baltagi } \\
\text { D. P. Rich }\end{array}$ & $\begin{array}{l}\text { Skill-Biased Technical Change in U.S. } \\
\text { Manufacturing: A General Index Approach }\end{array}$ & 1 & $08 / 03$ \\
\hline 842 & $\begin{array}{l}\text { M. Svarer } \\
\text { M. Rosholm } \\
\text { J. R. Munch }\end{array}$ & Rent Control and Unemployment Duration & 3 & $08 / 03$ \\
\hline 843 & $\begin{array}{l}\text { J. J. Heckman } \\
\text { R. Matzkin } \\
\text { L. Nesheim }\end{array}$ & Simulation and Estimation of Hedonic Models & 6 & $08 / 03$ \\
\hline 844 & D. Sliwka & On the Hidden Costs of Incentive Schemes & 1 & $08 / 03$ \\
\hline 845 & $\begin{array}{l}\text { G. Dewit } \\
\text { H. Görg } \\
\text { C. Montagna }\end{array}$ & $\begin{array}{l}\text { Should I Stay or Should I Go? A Note on } \\
\text { Employment Protection, Domestic Anchorage, } \\
\text { and FDI }\end{array}$ & 2 & $08 / 03$ \\
\hline 846 & $\begin{array}{l}\text { D. de la Croix } \\
\text { F. Docquier }\end{array}$ & $\begin{array}{l}\text { Diverging Patterns of Education Premium and } \\
\text { School Attendance in France and the US: A } \\
\text { Walrasian View }\end{array}$ & 6 & $08 / 03$ \\
\hline 847 & B. R. Chiswick & $\begin{array}{l}\text { Jacob Mincer, Experience and the Distribution of } \\
\text { Earnings }\end{array}$ & 1 & $08 / 03$ \\
\hline 848 & $\begin{array}{l}\text { A. Chevalier } \\
\text { G. Conlon }\end{array}$ & Does It Pay to Attend a Prestigious University? & 6 & $08 / 03$ \\
\hline 849 & W. Schnedler & Traits, Imitation, and Evolutionary Dynamics & 5 & $08 / 03$ \\
\hline 850 & $\begin{array}{l}\text { S. P. Jenkins } \\
\text { L. Osberg }\end{array}$ & $\begin{array}{l}\text { Nobody to Play with? The Implications of } \\
\text { Leisure Coordination }\end{array}$ & 5 & $08 / 03$ \\
\hline 851 & J. D. Angrist & $\begin{array}{l}\text { Treatment Effect Heterogeneity in Theory and } \\
\text { Practice }\end{array}$ & 6 & $08 / 03$ \\
\hline 852 & $\begin{array}{l}\text { A. Kugler } \\
\text { M. Kugler }\end{array}$ & $\begin{array}{l}\text { The Labor Market Effects of Payroll Taxes in a } \\
\text { Middle-Income Country: Evidence from } \\
\text { Colombia }\end{array}$ & 1 & $08 / 03$ \\
\hline 853 & $\begin{array}{l}\text { I. Ekeland } \\
\text { J. J. Heckman } \\
\text { L. Nesheim }\end{array}$ & Identification and Estimation of Hedonic Models & 6 & $08 / 03$ \\
\hline 854 & $\begin{array}{l}\text { A. Ferrer-i-Carbonell } \\
\text { B. M. S. Van Praag }\end{array}$ & Income Satisfaction Inequality and Its Causes & 3 & $08 / 03$ \\
\hline 855 & $\begin{array}{l}\text { B. Irlenbusch } \\
\text { D. Sliwka }\end{array}$ & $\begin{array}{l}\text { Career Concerns in a Simple Experimental } \\
\text { Labour Market }\end{array}$ & 1 & $08 / 03$ \\
\hline
\end{tabular}

An updated list of IZA Discussion Papers is available on the center's homepage www.iza.org. 